\section{Impact of a multidisciplinary pre- dialysis program on renal treatment modalities choice}

\section{Luis Miguel Castro Fonseca dos Santos Oliveira*, Rui Arlindo dos Santos Alves de Castro and Teresa Margarida Ribeiro Pinto Morgado}

Centro Hospitalar de Trás-os-Montes e Alto Douro EPE, Vila Real, Vila Real, Portugal

\section{Introduction}

In Portugal, around 2500 patients with end-stage chronic kidney disease (CKD stage 5) start a renal replacement therapy (RRT) for the first time each year [1]. They have four main treatment options: kidney transplantation (TX); haemodialysis (HD); peritoneal dialysis (PD) and conservative treatment (CT). RRT selection is quite complex due to the specificities of each option and to their profound effect on patient's quality of life. Patients must play a decisive role in the choice of treatment modality and select the option that best suits to their values and needs.

As nephrologists we should try to provide the best possible information to patients with chronic kidney disease helping them to make appropriate choices about their RRT. Patient involvement in making health decisions is becoming a central component of health care provision all around the world [2].

Furthermore, a meta-analysis on decision aids (educational material focusing on options and outcomes for the purpose of preparing people for decision making) helped people feel more informed about their options, more comfortable about their choices and also provides a clearer picture regarding personal values affecting their choices [3].

Previous studies have identified several factors associated with RRT selection, including the timing of referral, physician bias, predialysis education, resource availability, social and cultural status [4-6]. In contrast, a recently published registry study show that patients with early awareness of the method [7] were more likely to select self care dialysis and avoid unnecessary invasive procedures.

In line with our health public system directives [8] we promoted a pre-dialysis education prior to RRT initiation, helping patients to make an informed treatment decision treatment.

\section{Objective} in Portugal. was also analyzed.

\section{Methods}

More Information

*Address for Correspondence:

Luis Miguel Castro Fonseca dos Santos Oliveira Centro Hospitalar de Trás-os-Montes e Alto Douro EPE, Vila Real, Vila Real, Portugal, Email: luissoliveira06@yahoo.com

Submitted: April 01, 2021

Approved: May 04, 2021

Published: May 05, 2021

How to cite this article: dos Santos Oliveira LMCF, dos Santos Alves de Castro RA Morgado TMRP. Impact of a multidisciplinary pre-dialysis program on renal treatment modalities choice. J Clini Nephrol. 2021; 5 : 047-052.

DOI: 10.29328/journal.jcn.1001073

Copyright: @ 2021 dos Santos Oliveira LMCF, et al. This is an open access article distributed under the Creative Commons Attribution License, which permits unrestricted use, distribution, and reproduction in any medium, provided the original work is properly cited.

Wheck for updates

(1) OPEN ACCESS

since April 2011. We stress it is of greatly importance to minimize stress in this modality choice process, preserving quality of life, decreasing unnecessary invasive procedures and strengthening the active role of the patient in their own

Multidisciplinary pre dialysis education might increase selection of home-based therapies including PD, in other countries $[9,10]$. Nevertheless in Portugal their relevance has not has not been extensively studied.

In a retrospective single-center cohort study, we tried to identify the demographic, social and personal factors which influence patient choice of end-stage renal disease (ESRD) treatment modality (HD, PD and CT) in a single renal centre

The frequency distribution of dialysis modalities allocation between people attending our education program (since 2011) and those people not attending it (before 2011)

The influence of pre-dialysis education was retrospectively evaluated. During a 9 year period (2011-2019), we evaluated age, self-dialysis capacity and clinical issues (CKD 
etiology, hernias, obesity, abdominal surgeries). Incidence rates of $\mathrm{PD}, \mathrm{HD}, \mathrm{CT}$ choices for patients receiving predialysis education were compared. Patients who had kidney transplants were excluded.

Although national practice varies, we refer our own CKD patients with glomerular filtration $<20 \mathrm{ml} /$ minute to Educational intervention, which includes at least one appointment with a nephrologist, a nurse and nutricionist. Social and psycological support is assured according to patient needs. Visits to hemodialysis and peritoneal dialysis units are also provided including some chat with patients already on RRT; and written and audio-visual materials to take home.

All patients received two written manuals. The first is an official recommendation of Directorate-General of Health, Portugal - DGS, entitled "Esclarecimento para facultar um consentimento informado para opção de tratamento da insuficiência renal crónica avançada" that describes dialysis and medical therapy. The other written manual of the Portuguese Society of Nephrology explains the potential advantages of self care dialysis in detail.

We have also collected demographic, clinical and social data as age, diabetes, cause of CKD, duration of Nephrology consultation, creatinine clearance (in 24-hour urine), selfdialysis capacity, and clinical contraindication for each dialysis modality, Charlson índex and Bansal score.

The Six-item Cognitive Impairment Test (6CIT) was designed to assess global cognitive status.

Continuous symmetrically distributed data was expressed as mean \pm standard deviation. Asymmetrically data was expressed as median and range. Categorical data are expressed as absolute numbers and percentages.

Significant variations between the study groups were tested using the Mann-Whitney U-test. Differences in the relative frequencies were tested using Pearson chi-square test.

\section{Results}

Eight hundred and thirteen patients were included in our study. Their characteristics of the patients are described in table 1 .

We like to emphasize they were 76 [22-100] years and there was no gender predominance. Two hundred and fifty five patients were diabetic (31.4\%). Glomerular filtration rate at the moment of evaluation was 17 [0-36] $\mathrm{ml} / \mathrm{min}$.

The bulk of those patients (93\%; $n=783$ ) were previously followed in nephrology consultation for about 5 [0-285] months. The remaining were refered after/during hospitalization by the assistant nephrologist.
The main etiologies of renal disease were: diabetic nephropathy (31\%), unknown causa (26\%), chronic pyelonephritis (11\%), glomerulonephritis (6\%), Kidney allograft failure (4\%), Cardio-Renal Syndrome (3\%), ischemic nephropathy (3\%) and polycystic kidney disease (3\%).

Overall 59\% ( $n=482$ ) chose hemodialysis (HD), 19\% $(n=155)$ peritoneal dialysis (PD) and 12\% $(n=100)$ conservative management (CT). The remaining 76 (9.4\%) patients were poor candidates for dialysis and clinically selected to conservative management.

The median number of patient visits to the hospital was 1.7 [1-5] and 50.1\% $(n=407)$ of them had a definitive decision at the second visit. The mean time to patient's decision was independent of their final choice.

Clinical and social issues played an important role in the decision process (Tables 2,3).

One hundred and ninety patients had no clinical or social indication for PD or HD and thus were capable to make their own choice. They divided themselves equally between those modalities. Contrarily CT decision was unquestionably affected by clinical factors (free choice for only 2.6\%) PD selection was associated with younger age (61 \pm 16 vs. $86 \pm 6$ vs. $73 \pm 13$ years; $p<0.05$, respectively) and less co-morbid conditions (Charlson index of $4.5 \pm 2.3$ vs. $7.8 \pm 1.4$ vs. $6.1 \pm 2.2$; $p<0.05$, respectively) compared to CT and HD.

Twenty eight of the one hundred and fifty five patients (18\%) who opted for peritoneal dialysis had a relative contraindication, so evaluation by general surgery was requested and hernias were corrected before or during

\begin{tabular}{|c|c|}
\hline & $(n=813)$ \\
\hline Gender & M 49.6\%; F 50.4\% \\
\hline $\begin{array}{c}\text { Patients' age at the beginning of the PDE monitoring } \\
\text { (years) }\end{array}$ & $76[22-100]$ \\
\hline $\begin{array}{c}\text { Creatinine clearance at the start of the education } \\
\text { process }(\mathrm{ml} / \mathrm{min})\end{array}$ & $17.0[6.0-36.0]$ \\
\hline Average number of patient visits until the final choice & $1.7 \pm 0.8$ \\
\hline Diabetes (\%) & 31.4 \\
\hline Previous nephrological follow-up (months) & $5[1-285]$ \\
\hline BANSAL Score & $94[3-94]$ \\
\hline Kidney Failure Risk & $20[2-56]$ \\
\hline
\end{tabular}

\begin{tabular}{|c|c|c|c|}
\hline & $\begin{array}{c}\text { PD }(19,1 \%) \\
n=155\end{array}$ & $\begin{array}{c}\text { HD }(59,2 \%) \\
n=482\end{array}$ & $\begin{array}{c}\text { CT }(21,6 \%) \\
n=100\end{array}$ \\
\hline Age (years) & $60.8 \pm 16.0^{*}$ & $72.6 \pm 13.3^{*}$ & $86.5 \pm 6.4^{*}$ \\
\hline Male (\%) & 59.4 & 51.4 & 43.0 \\
\hline Creatinine clearance $(\mathrm{ml} / \mathrm{min})$ & $17.7 \pm 9.9$ & $16.3 \pm 4.3$ & $18.0 \pm 6.5$ \\
\hline Diabetes (\%) & 26.4 & 35 & 27.0 \\
\hline $\begin{array}{c}\text { Contraindication for another } \\
\text { technique }(\%)\end{array}$ & $6,4^{*}$ & $41,0^{*}$ & $89^{*}$ \\
\hline Charlson score & $4,5 \pm 2,3^{*}$ & $6,1 \pm 2,2^{*}$ & $7,8 \pm 1.4^{*}$ \\
\hline BANSAL score & $48,9 \pm 21,3^{*}$ & $66,6 \pm 21,6^{*}$ & $85,1 \pm 18,1^{*}$ \\
\hline Option (\%) & $10,0(n=81)$ & $10,9 \quad(n=88)$ & $2,6^{*}(n=21)$ \\
\hline Inability to auto-dialysis (\%) & $5,7(n=46)$ & $48,4(n=394)^{*}$ & $9,7(n=79)$ \\
\hline Contraindication for PD & $3,4(n=28)$ & & \\
\hline
\end{tabular}


Table 3: Causes of inability to auto-dialysis, contraindication for peritoneal dialysis. Option ( $n=190)$ Inability to auto-dialysis /PD $(n=519)$ Contraindication for PD $(n=28) \quad$ Contraindication for RRT ( $n=76)$

\begin{tabular}{|c|c|c|c|c|}
\hline & Option $(n=190)$ & Inability to auto-dialysis /PD $(n=519)$ & Contraindication for PD $(n=28)$ & Contraindication for RRT ( $n=76)$ \\
\hline Peritoneal Dialysis $(n=155)$ & 88 & & $\begin{array}{c}\text { 24-hernias } \\
\text { (4-obesity* } \\
\text { 3-previus surgeries) }\end{array}$ & \\
\hline $\begin{array}{l}\text { Hemodialysis } \\
\quad(n=482)\end{array}$ & 81 & $\begin{array}{l}\text { 341-cognitive impairment } \\
65-\text { functional limitation } \\
\text { 34- lack of visual acuity }\end{array}$ & $\begin{array}{c}\text { 62-Obesity } \\
\text { 26-Hernias } \\
\text { 4-Ascites } \\
\text { 4-Colostomy } \\
\text { 3-Eventration } \\
\text { 1-Diverticulite } \\
\left(16-\text { Hernias*) }^{*}\right. \\
(6-\text {-Eventration*) } \\
\text { (3-diverticulosis*) } \\
\text { (5-colostomy*) }\end{array}$ & \\
\hline Conservative management $(n=176)$ & 21 & $\begin{array}{l}\text { 69- cognitive impairment } \\
10 \text { - functional limitation }\end{array}$ & & $\begin{array}{l}\text { 69-Severe dementia } \\
\text { 2- Huntington disease } \\
\text { 2-major stroke sequela } \\
\text { 3- neoplasia }\end{array}$ \\
\hline
\end{tabular}

placement. of the DP catheter. Seven patients had several contraindications to perform PD such as moderate to severe obesity and previous abdominal surgeries. Tenckhoff catheter implantation was requested for 22 of the patients who opted for peritoneal dialysis (clearance creatinine $<15 \mathrm{ml} /$ minute).

The lack of autonomy and capacity for self-dialysis (6CIT>8) of increasingly elderly and highly comorbid patients $(n=519 ; 63,8 \%)$, associated with the lack of a support network for assisted dialysis (by family member, health professionals or employee at retirement homes) has been a very important limiting factor for the growth of our PD program. Nevertheless, we were able to provide a peritoneal dialysis helper in 46 cases (Table 3 ).

From the forty-nine patients (10\%) who opted for hemodialysis and had already arteriovenous fistula (AVF), 16 were referred for consultation of vascular access due to poor maturation.

Four hundred and thirty-nine patients underwent a clinical and imaging evaluation of their vascular heritage (creatinine clearance $<17 \mathrm{ml} / \mathrm{min}$ ) to create a vascular access. Seven had recovery of renal function, so the construction of AVF was postponed.

One hundred patients (12\%) opted for CT, an option conditioned by their inability to self-dialysis. This is a reflection of the elderly population followed in our Nephrology Consultation and the geographical situation of our region, as many patients live far away from a Hemodialysis Center. It can also represent an evolution in the mentality of both patients and family members, favoring comfort and quality of life over invasive organ support measures or frequent contact with the health system. In fact, these patients were older (86 \pm 6 vs. $70 \pm 15$ years) had higher morbidity (Charlson index of $7.8 \pm 1.4$ vs. $5.7 \pm 2.3$ ) and higher mortality risk compared to those who have selected dialysis $(85.1 \pm 18.1 \mathrm{vs}$. $62.3 \pm 22.7$, respectively) .

The remaining 76 patients ( $9 \%$ ) had no clinical indication for RRT. Only 10 patients needed evaluation by the Social Welfare.
All patients who were assigned to CT continued the followup at the chronic renal disease division of our Nephrology Department and were offered palliative care as needed.

Gender, glomerular filtration and diabetes were not associated whatsoever to RRT option.

A sustained growth of PD incidence in our Department (Graphic 1) was noticed mainly in the first years of the development of this pre-dialysis education program $(5.9 \%$ vs. $15.2 \%$ ).

\section{Discussion}

Pre-dialysis education helps to overcome fears about dialysis and helps patients to choose a dialysis modality. Several studies have shown that it also might help to increase self-care dialysis $[9,10]$. In contrast, a recently registry study did not show that patients with early awareness of PD were prone to select it [10] were more likely to select PD.

Amongst individuals who do have free choice, CT was the less taken option (2.6), and the 2 dialysis modalities were equally seelcted (10\% each).

Modality selection was mainly based on a mix of medical and non-medical factors. While some of these are nonmodifiable, such as age and degree of co-morbidity, others draw attention to the importance of non-biased information

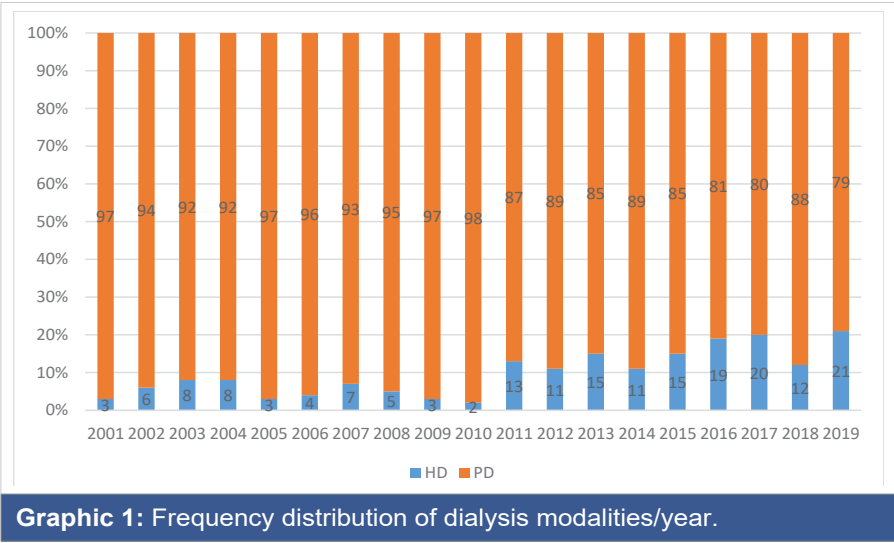


and pre-dialysis education in empowering socially able patients to choose self-care therapies.

In our experience, 813 patients were submitted to predialysis education program. Fifty nine per cent of patients had chosen HD, 19\% PD and 12\% were selected for CT. Similar results were described in other studies [11] Seventy six patients were considered poor candidates to RRT and were consequentely CT.

Despite autonomy loss, the need for needling, vascular access issues and dietary restrictions, hemodialysis was favorite treatment maybe because of a safety feeling, related to a hospital/hemodialysis center environment and caring and helpfulness of nurses and dialysis staff, and some intuition from the patients and caregivers that the health staff will provide immediate response to any drawbacks like pain by staff to immediate needs (pain, discomfort, sterile procedures) [12].

Peritoneal dialysis was the second RRT chosen (19\%). According to a British report, $45 \%$ of the patients embrace PD as the final treatment choice and the definitive treatment, provided the patients had gone through the EP [13]. In contrast to those optimistic studies from a decade ago, a recently survey on patient awareness of PD for the Comprehensive Dialysis Study revealed that $61 \%$ of the patients reported hearing some information about PD, but only $10.9 \%$ initiated PD. Nevertheless, in the same survey only $1.6 \%$ of patients not informed about the PD treatment option started with PD [12].

In Portugal, PD still remains clearly underutilized. According to the 2018 registry of the Portuguese Society of Nephrologhy annual PD incidence is about 3,8\% (37.3\% for renal transplantation and $58.9 \%$ for HD, without official data on CT choice). In our country, dialysis services are totally financed by the State and reimbursed at a fixed rate/patient/ week called "comprehensive price payment". However, almost $90 \%$ of the patients with chronic kidney disease are treated in hemodialysis private units.

As described in other studies there was a clear association between age and modality choice. Mean age of patients choosing PD was 61 years compared to 73 years for HD and 87 years for CT $(p<0.001)$. Similarly, the degree of morbidity burden was linked with treatment choice, such as patients choosing PD having mean CI score of 4.5 compared to 6.1 among HD patients and 7.8 for CT $(p<0.001)$.

According to a British report, $45 \%$ of CKD5 educated patients chose PD as their RRT [12]. Similar results were obtained in the National Pre-ESRD Education Initiative: $45 \%$ chose PD after being educated about RRTs [13].

In contrast to those optimistic studies, we reported a lower PD incidence. At baseline, our PD rate was even lower
$(<8 \%)$ probably because of fears and great anxiety of these patients before starting dialysis concerning to long-term health issues, lifestyle changes, self-dialysis capacity and modality safety.

We consider that this multidisciplinary pre-dialysis program demystified some of these worries and ensured that peritoneal dialysis can actually be less stressful, less painful and less lifestyle altering than in-center hemodialysis.

Nevertheless, we studied an elderly population with impaired manual dexterity, decrease visual acuity and social isolation which contributes to lack of self-dialysis capacity. These results most certainly represent a marker of great comorbidity and lesser functional ability among this group of patients that also account for barriers that restrict patient choice of treatment modality.

Vila Real district has lost, since the beginning of the 21 st century until 2017, $13 \%$ of its population, about 30000 inhabitants. Twenty six per cent of the 193715 district residents in 2017, were 65 years or older. A senior population that surpasses, for example, the entire population of the district capital municipality, Vila Real. Of these about 50000 seniors, according to data from Guarda Nacional Republicana's 2017 Senior Census, 3827 live in solitude and/ or isolation. $8 \%$ of the senior population of Vila Real district ( $2 \%$ of the total) lives with no one to care for them.

In economic terms, according to official data (INE/ PORDATA), the elderly population (over 65 years old) in the diocese of Vila Real is currently comprised of 47242 individuals, reaching in some municipalities almost 30\% of residents. The individual average income is expected to be around $€ 400 €$, which represents $35 \%$ of the average national income.

The majority of this population (98\% for men and $77 \%$ for women) is retired people, whose main source of income is unilateral transfer from the state on grounds of offsetting the contribution. During the contributory life, by the diminished accumulation of capital or savings or by offsetting the consequences of diminishing accidents of expected productivity.

Even though, we were able to assure assisted DP in 46 patients involving family and nursing staff. At our centre, it will be difficult to achieve higher DP rates due to organizational, structural and logistic difficulties to provide social support for this kind of patients. We consider that changes in national public policy may lead to an expansion in the use of PD like has occurred in many parts of the world, as the Portuguese government does not promote nurse home care to support peritoneal dialysis.

In our population, clinical issues were also contraindications for HD such as poor cardiovascular status $(n=10)$. 
Increased co-morbidity and lesser functional ability account for barriers that restrict patient choice of treatment modality. These patients are more likely to opt for CT. In fact, life expectancy in older, frail and multimorbid patients is likely to be similar on conservative management programs comparing to life expectancy on dialysis, especially when days spent as inpatients or on dialysis are excluded. Larger studies are also needed because many of the landmark papers involved fewer than 100 participants.

The patient's refusal to undergo dialysis treatment was the reason for including them in the conservative treatment group (12.3\%). A similar percentage of patient's decision $(14,6 \%)$ was described in the series of an australian observational study [14]. As previously mentioned, variables associated to a preference for CT was age and Charlson index as these patients might feel that dialysis could cause them to have poor quality of remaining life. In such situations, it is important to have a clear view and discuss individual problems, circumstances and advantages and disadvantages of dialysis, between the patient, relatives and carers. Ongoing care is always provided by the renal team, and possibly by the palliative care team.

There is little information available on the percentage of patients with CKD on conservative therapy in Portugal and the available data in other countries is very variable $(8.4 \%-62.4 \%)$ due to the great disparity of the population under analysis and selection critera. In a spanish report, CT was selected by $39 \%$ of patients [15].

Mortality risk assessed by Bansal score was greatly higher in the group of patients assigned to conservative treatment in comparison to HD and DP: $85.1 \pm 18.1,66.6 \pm 21.6$ and 48.9 $\pm 21.3(p<0.001)$.

\section{Limitations}

Besides its retrospective design, this study only evaluated the modality that patients intended to select rather than the modality that they actually started. Quality of life was also another parameter not evaluated.

\section{Conclusion}

Our multidisciplinary pre-dialysis program had a significant impact on the frequency distribution of dialysis modalities, increasing the proportion of patients initiating dialysis with PD. Such interventions should stress the advantages of self-care dialysis most likely as increased freedom and lifestyle preservation. Furthermore, the lack of a strong social support network and functional ability of these old population, emphasizes the need for assisted PD. We hope to incorporate these changes into our pre-dialysis education to increase the uptake of self-care modalities in the future.

This study also highlights that factors like age, functional status and morbidity may also influence ESRD patient choice of treatment modality including CT.

However, in order to deliver a good service, full multidisciplinary team support and good communication between primary and secondary care is essential. Looking to the future, standardized definitions and a registry of conservative management must be developed in order to improve and standardize research in this area.

Nevertheless, these results cannot be generalized to other parts of Portugal due to regional variation of social, economical and demographic profile. These data must be taken into account and compared to the experience at other centres in order to gain precise knowledge of the major factors influence patient choice of different treatment modalities at the pre-dialysis stage.

We reported that our educational intervention increased the proportion of patients who select self-care dialysis. In the study, using qualitative analysis we found that our educational intervention increased patients' perceptions of the advantages of SCD and that these perceptions, in turn, were associated with choosing SCD.

\section{References}

1. Galvão A, Filipe R, Carvalho M. Relatório Gabinete de Registo da SPN. Portuguese registry of dialysis and transplantation 2017 Encontro renal março de 2018. Vilamoura: SPN. 2018.

2. Gulland A. Welcome to the century of the patient. BMJ.2011;342:d2057. PubMed: https://pubmed.ncbi.nlm.nih.gov/21471162/

3. O'Connor A, Stacey D, Lewis K, Barry MJ, Bennett CL, et al. Decision aids for people facing health treatment or screening decisions (Review). Cochrane Database Sys Rev. 2009; 3: CD001431. PubMed: https://pubmed.ncbi.nlm.nih.gov/28402085/

4. Smart N, Titus T. Outcomes of early versus late nephrology referral in chronic kidney disease: a systematic review. Am J Med. 2011; 124: 1073-1080.

PubMed: https://pubmed.ncbi.nlm.nih.gov/22017785/

5. Chiang P, Jia-Jeng H, Ing-Ching J, Peir-Haur H3, Chih-Yen H, et al. Factors Associated with the Choice of Peritoneal Dialysis in Patients with End-Stage Renal Disease. BioMed Res Int. 2016; 2016: 5314719.

6. Kutner $\mathrm{N}$, Zhang $\mathrm{R}$, Huang $\mathrm{Y}$, Wasse $\mathrm{H}$. Patient awareness and initiation of peritoneal dialysis. Arch Intern Med. 2011; 171: 119-124. PubMed: https://pubmed.ncbi.nlm.nih.gov/20876396/

7. DGS - Tratamento Conservador Médico da Insuficiência Renal Crónica Estádio 5. Norma nº 017/2011. 2011.

8. Goovaerts T, Jadoul M, Goffin E. Influence of a Pre Dialysis Education Programme (PDEP) on the mode of renal replacementtherapy, Nephrology Dialysis Transplantation. 2005; 20: 1842-1847.

PubMed: https://pubmed.ncbi.nlm.nih.gov/15919693/

9. Little J, Irwin A, Marshall T, Rayner H, Smith S. Predicting a patient's choice of dialysis modality: experience in a United Kingdom renal department. Am J Kidney Dis. 2001; 37: 981-986.

PubMed: https://pubmed.ncbi.nlm.nih.gov/11325680/

10. Dimitrios C, Khai N, Bassam F, Baharani J. What influences patient choice of treatment modality at the pre dialysis stage? Nephrol Dial Transplant. 2012; 27: 1542-1547.

PubMed: https://pubmed.ncbi.nlm.nih.gov/21865216/ 
11. Palmer S, Berardis G, Craig JC, Tong A, Tonelli M, et al. Patient satisfaction with in-centre haemodialysis care: an international survey. BMJ Open. 2014; 4: e005020.

PubMed: https://pubmed.ncbi.nlm.nih.gov/24840250/

12. Golper T. Patient education: can it maximize the success of therapy? Nephrol Dial Transplant. 2001; 16: 20-24.

PubMed: https://pubmed.ncbi.nlm.nih.gov/11590252/

13. Tejedor A, Sanz F, Perez N. Atención domiciliaria al paciente urémico terminal no susceptible de diálisis. Nefrología. 2006; 26: 66-81.
14. Morton RL, Turner RM, Howard K, Snelling P, Webster AC. Patients who plan for conservative care rather than dialysis: a National Observational Study in Australia. Am J Kidney Dis. 2012; 59: 419-427. PubMed: https://pubmed.ncbi.nlm.nih.gov/22014401/

15. Teruel J, Vion V, Couto A, Gorrín MR, Fernández-Lucas M, et al. Choosing conservative therapy in chronic kidney disease. Nefrologia. 2015; 35: 273-279.

PubMed: https://pubmed.ncbi.nlm.nih.gov/26299170/ 